\title{
Modelica Modelling of an Ammonia Stripper
}

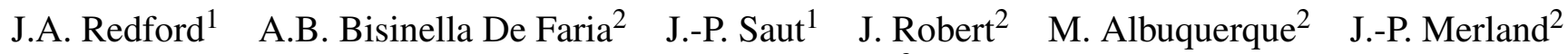 \\ J.-M. Ghidaglia ${ }^{3}$ \\ ${ }^{1}$ Eurobios SCB, 61 av. du Président Wilson, Cachan, France. jredford@eurobios.com \\ ${ }^{2}$ Veolia Recherche \& Innovation, Chemin de la Digue, Maisons-Laffitte, France. \\ ${ }^{3}$ CMLA, ENS Paris Saclay, 61 av. du Président Wilson, Cachan, France.
}

\begin{abstract}
This work presents a Modelica model for an ammonia stripper that is used to process waste (digestate) from a biogas production unit. The model includes the chemical balance equations between species in the liquid and gas, and includes the exchanges between both phases and the energy consumption of the unit. Results show the expected behaviour with an increasing $\mathrm{p} H$ with time, with further validation and calibration being necessary once experimental results are available. This is a novel use of Modelica designed to expand the library of processes that are simulated using this approach.
\end{abstract}

Keywords: nutrients recovery, chemical reactions, process engineering, environment

\section{Introduction}

Today, the balance between the requirement for a resource and its availability has changed. This has led to a paradigm shift from resource consumption that is followed by a waste production to a use-and-recover approach, which converts the waste into a product. However, in order to reduce environmental impact and increase nutrient recycling there is a growing demand for predictive tools that might help to better manage these processes and close the recycling loop.

In this context, anaerobic digestion has been studied over the last decades and is known today as a process that allows recovery of large amounts of energy by producing biogas. However, the residual flow of the digested product, known as a digestate, needs to be valorized in order to fully capitalize on the nutrient recycling, in addition to the conventional energetic valorization. The digestate has, among other nutrients, large amounts of nitrogen that can be used as fertilizers on agricultural land. Traditionally, the residual nitrogen is treated (by nitrification and denitrification for instance) without the aim of recovering the nitrogen. However, as resource recovery is gaining interest, several technologies are available today that valorize the nitrogen in the digestate, in order to produce an environmental, legislative and cost friendly byproducts.

Among the most used technologies, one may cite ammonia stripping, struvite precipitation and membrane processes. Struvite $\left(\mathrm{NH}_{4} \mathrm{MgPO}_{4} \cdot 6 \mathrm{H}_{2} \mathrm{O}\right)$ is a slow-release fertilizer, however its nitrogen concentration is limited and the precipitation is triggered by magnesium, which demands the addition of chemical products. Concerning membrane processes, pretreatment techniques are required in order to increase the membrane lifetime. Therefore, ammonia stripping is a low cost technique that allows recovery of nitrogen from a liquid phase to a gas phase, and then via an acid scrubber it is possible to recover a nitrogen salt, such as the ammonium sulphate salt $\left(\mathrm{NH}_{4}\right)_{2} \mathrm{SO}_{4}$.

The objective of this study is to develop a model capable of predicting nitrogen removal from a digestate and how this is impacted by variation of the main influencing operational parameters. When calibrated, this model can be used to predict stripping performance, envisage other process configurations, optimize recovery and estimate operational costs. In order to be easily used in different contexts, the developed model should include the possibility to simulate both mass and energy balances, along with the kinetics of the physico-chemical and liquid to gas transfer reactions involved in the process. It is also important to have the capacity for expansion in order to allow future enrichment by experimental results, as well as the use of the module, both in-situ and in a larger context of plant-wide modelling approach.

\subsection{Process engineering using Modelica}

The use of Modelica in chemical process engineering is developing quickly. While Jain et al. (2017) state that 'OpenModelica ... lacks good chemical engineering support', much work is under way to correct this. MarxSchubach and Schmitz (2017) have created a library and model for an absorber used in a carbon capture process. Åkesson et al. (2011) model carbon capture, which involves stripping. They include chemistry for a system of equations along with calculation of equilibrium equations. Comparison is made with experimental results. Baharev and Neumaier (2012) aim to create the foundations of a general purpose library for chemical process modelling. Joos et al. (2009) model several chemical processes (absorption, adsorption and rectification). Küssel et al. (2009) model rotary kilns (i.e. combustion) and make comparisons with computational fluid dynamics (CFD) simulations. Both approaches showing good correspondence, but Modelica is less computationally demanding, which 
means that the authors' aims for real time operation in control loop is realistic. Cellier and Greifeneder (2009) carried out simulations of basic reactions to demonstrate the use of Modelica for simulation of chemical reaction systems in an object-oriented physically inspired manner.

Windahl et al. (2015) develop a library of thermodynamic properties and give an air separation column with multiple stages as a test case. CAP-OPEN (ComputerAided Process Engineering-OPEN) is used and there is strong interest in the interface structure linking Modelica and external libraries. Tummescheit and Eborn (2002) add support to 'ThermoFluid' for chemical reactions and membrane diffusion.

De Canete et al. (2013) use Modelica for simulation of distillation columns. They have accounted for the column trays with multiple stacked trays. This work is aimed at developing a control system with an Neurofuzzy network approach.

Concerning ammonia stripping, Vaneeckhaute et al. (2018) recently published a generic nutrient recovery model (NRM) library that is mainly coded in Modelica and based on detailed chemical solution speciation and reaction kinetics for nitrogen recovery.

\section{The Model}

A simplified model for an ammonia bubble stripper is now presented. Figure 1 shows the basic configuration of the simplified stripper along with the inputs, outputs and the processes under consideration. Digestate enters the stripper with a given flowrate and initial composition. Air is added at the base of the stripper with a given temperature and relative humidity. At the top, the result is a stripped gas containing air, water and ammonia. The liquid output is the digestate with reduced TAN (total ammonia nitrogen). Heat is lost from the liquid through warming of the gas and the liquid to gas water mass transfer (evaporation). Hence, heating is required to maintain the digestate at the correct temperature and this represents one of the running costs of the stripper unit.

With respect to the gas phase, the stripper is split into slices that are stacked vertically. The liquid phase is assumed to be fully mixed and is represented as a single entity. As the gas bubbles rise they will gradually strip the ammonia from the liquid phase.

\subsection{Chemical equations}

In Figure 2 the model inputs are in red and the outputs are in blue. The internal processes are in green, where the mass balances include $\mathrm{NH}_{3(\mathrm{aq})}, \mathrm{NH}_{4}^{+}, \mathrm{HCO}_{3}^{-}, \mathrm{CO}_{3}^{2-}$, $\mathrm{CO}_{2 \text { (aq) }}, \mathrm{N}_{\text {org }}, \mathrm{H}_{2} \mathrm{O}, \mathrm{H}^{+}$and $\mathrm{OH}^{-}$species for the liquid phase, $\mathrm{NH}_{3}, \mathrm{CO}_{2}$ and $\mathrm{H}_{2} \mathrm{O}$ species in the gas phase. The energy balance includes water vaporisation and air heating. In order to model this process we must consider the chemical equilibrium between the TAN and DIC (dissolved inorganic carbon) species, the mass transfer of $\mathrm{NH}_{3}, \mathrm{CO}_{2}$ and $\mathrm{H}_{2} \mathrm{O}$ between liquid and gas, and an energy balance. The dynamics in the column depend on time (for both liquid and gas concentrations) and column height (gas concentration), meaning that the stripping column has to be discretised spatially and temporally.

\subsubsection{Modelling $\mathbf{p} H$ and species concentrations}

In the liquid phase three conjugate acid-base pairs are considered here; $\mathrm{NH}_{3(\mathrm{aq})} / \mathrm{NH}_{4}^{+}, \mathrm{HCO}_{3}^{-} / \mathrm{CO}_{3}^{2-}$ and $\mathrm{HCO}_{3}^{-}$ $/ \mathrm{CO}_{2(\mathrm{aq})}$. Initially focusing on nitrogen species, two reactions might be written as follows

$$
\mathrm{NH}_{3}+\mathrm{H}^{+} \rightarrow \mathrm{NH}_{4}^{+},
$$

with reaction rate $k_{a}$ (kinetic constant of association), and

$$
\mathrm{NH}_{4}^{+} \rightarrow \mathrm{NH}_{3}+\mathrm{H}^{+},
$$

with a reaction rate $k_{d}$ (kinetic constant of dissociation). Therefore, for the association, it is possible to relate the species concentrations with

$$
\frac{d\left[\mathrm{NH}_{4}^{+}\right]}{d t}=k_{a}\left[\mathrm{NH}_{3}\right][\mathrm{H}+]
$$

and for the dissociation

$$
\frac{-d\left[\mathrm{NH}_{4}^{+}\right]}{d t}=k_{d}\left[\mathrm{NH}_{4}^{+}\right] .
$$

The absolute association rate equals dissociation, thus

$$
\begin{aligned}
k_{a}\left[\mathrm{NH}_{3}\right]\left[\mathrm{H}^{+}\right] & =k_{d}\left[\mathrm{NH}_{4}^{+}\right], \\
{\left[\mathrm{NH}_{3}\right]\left[\mathrm{H}^{+}\right] /\left[\mathrm{NH}_{4}^{+}\right] } & =\frac{k_{d}}{k_{a}}=K_{a},
\end{aligned}
$$

where $K_{a}$ is the acid dissociation constant. Similarly, equations for chemical equilibrium might be arranged for $\mathrm{NH}_{4}^{+}$, for example, as "Association - Dissociation", giving

Chemical rate $\mathrm{NH}_{4}^{+}=-k_{d}\left[\mathrm{NH}_{4}^{+}\right]+\left(k_{a}\left[\mathrm{NH}_{3}\right]\left[\mathrm{H}^{+}\right]\right)$.

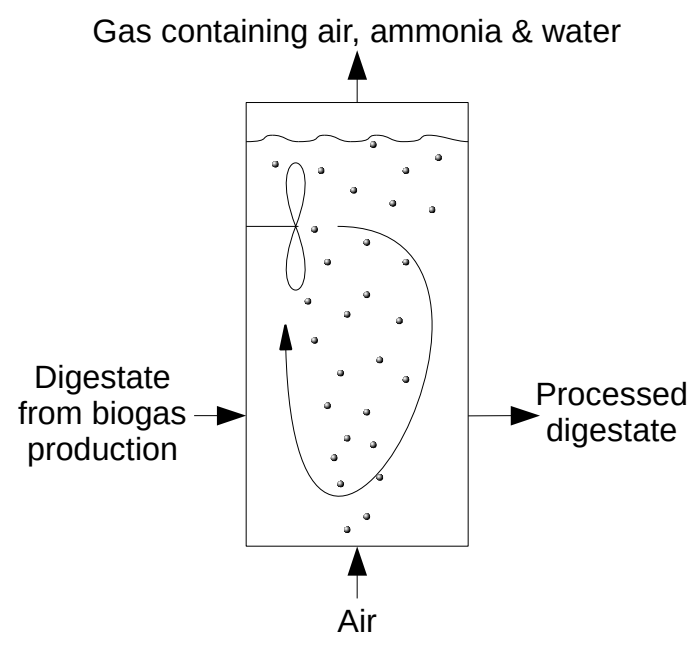

Figure 1. Stripping column exchanges. 
This same approach can be applied to the other chemical reactions. Values for $K_{a}$ are found from the LLNL ${ }^{1}$ database in the form of $-\log K_{a}$. These values might also be expressed as $\mathrm{p} K_{a}$, which represents $-\log K_{a}$. (Note that, $-\log \left[\mathrm{H}^{+}\right]=\mathrm{pH}$.)

Using the $\mathrm{p} K_{a}$ and $\mathrm{pH}$ definition equations, the liquid $\mathrm{NH}_{3}$ fraction, which will be partially transferred to the gas in the transfer step, can be calculated using

$$
f_{\mathrm{NH}_{3}}=\frac{10^{\mathrm{p} H-\mathrm{p} K_{a, \mathrm{NH}_{4}^{+} / \mathrm{NH}_{3}}}}{10^{\mathrm{p} H-\mathrm{p} K_{a, \mathrm{NH}_{4}^{+} / \mathrm{NH}_{3}}+1}} .
$$

Therefore, from TAN, the ammonia concentration in liquid is given by

$$
C_{\mathrm{NH}_{3}}=f_{\mathrm{NH}_{3}} \text { TAN, }
$$

and by definition,

$$
f_{\mathrm{NH}_{4}^{+}}=1-f_{\mathrm{NH}_{3}} .
$$

The same classical approach can be applied to find the DIC composition, which will not be given here to save space. The values of $k_{a}$ and $k_{d}$ depend on the kinetics and can be obtained experimentally. However, the kinetic rate constants are fixed at high values to ensure that the species present in the system almost instantaneously reach chemical equilibrium. This approach was proposed by Lizarralde et al. (2015).

\subsubsection{Gas transfer}

At time $t$ the liquid concentrations will be constant across all the column slices, i.e. completely mixed, and the gas concentration will change with height/slice. As with the real process, equilibrium between aqueous and bubble gaseous phases is not reached by top of column, meaning that the bubbles will leave the stripper without being

\footnotetext{
${ }^{1}$ Lawrence Livermore National Laboratory
}

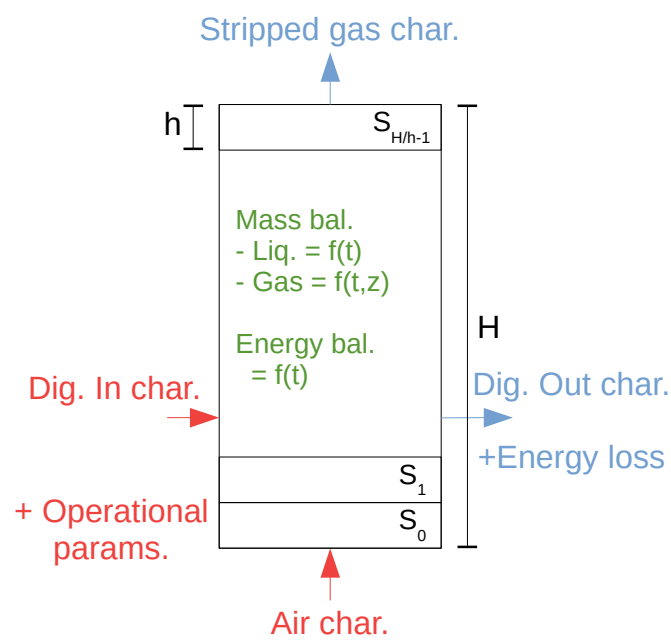

Figure 2. Stripping column schematic. saturated in $\mathrm{NH}_{3}$. The mass transfer from the liquid to each gas slice is calculated using the mass transfer rate described in Matter-Müller et al. (1981). For $\mathrm{NH}_{3}$

$$
M_{\mathrm{NH}_{3}, \text { liquid to gas }}=k_{L, \mathrm{NH}_{3}} a V_{L}\left(C_{\mathrm{NH}_{3}, \text { liq }}-C_{\mathrm{NH}_{3}}^{*}\right) \text {. }
$$

The gas bubbles are not perfectly spherical, and they will also coalesce and turbulence will cause them to break up. So, it is not possible to calculate the transfer area $a$. Also, a real digestate contains a significant concentration of suspended solids and other ionic species, which makes deriving a value of mass transfer coefficient $k_{L}$ difficult. Instead, a global value of $k_{L} a_{\mathrm{NH}_{3}}$ is found experimentally, hence

$$
M_{\mathrm{NH}_{3} \text {, liquid to gas }}=k_{L} a_{\mathrm{NH}_{3}} V_{L}\left(C_{\mathrm{NH}_{3}, \text { liq }}-C_{\mathrm{NH}_{3}}\right) \text {. }
$$

Considering liquid gas transfer, Henry's law describes relationship between gas concentration (expressed by its partial pressure in atm) and the saturation liquid concentration $C_{\text {liq }}^{*}$. For instance, in the case of $\mathrm{NH}_{3}$

$$
\begin{aligned}
\mathrm{NH}_{3(a q)} \leftrightarrow \mathrm{NH}_{3(g)} \text { with } \\
\begin{aligned}
K_{e, \mathrm{NH}_{3}\left(25^{\circ} \mathrm{C}\right)} & =\left[\mathrm{NH}_{3(g)}\right] /\left[\mathrm{NH}_{3(a q)}\right] \\
& =0.016 \mathrm{~atm} /(\mathrm{mol} / \mathrm{kg}),
\end{aligned}
\end{aligned}
$$

with $\left[\mathrm{NH}_{3(g)}\right]$ expressed as a partial pressure of $\mathrm{NH}_{3}$.

Also, from Matter-Müller et al. (1981)

$$
C_{\mathrm{liq}}^{*}=C_{g} / H^{c c},
$$

where $H^{c c}$ is Henry's dimensionless constant. $1 / H^{b p}$ values are available in $\mathrm{atm} /(\mathrm{mol} / \mathrm{kg})$ units and conversion to a dimensionless constant can be obtained using

$$
\begin{aligned}
H^{b p} & \approx H^{c p} / \rho_{\mathrm{H}_{2} \mathrm{O}}, \\
H^{c c} & =H^{c p} R T,
\end{aligned}
$$

where $\rho_{\mathrm{H}_{2} \mathrm{O}}$ is the solvent density $\left(\mathrm{kg} / \mathrm{m}^{3}\right), R$ is the universal gas constant $\left(8.206 \times 10^{5} \mathrm{~m}^{3} \mathrm{~atm} /(\mathrm{K} \mathrm{mol}), T\right.$ is the temperature $(\mathrm{K})$ and $H^{c p}$ is given in $\mathrm{mol} /\left(\mathrm{m}^{3} \mathrm{~atm}\right)$.

The mass balance equations for all species in both liquid and gas phases can be found from chemical equilibria and liquid/gas transfer equations. For any liquid species, HA, present in the column and supposing that $\mathrm{HA} \leftrightarrow \mathrm{H}^{+}+\mathrm{A}^{-}$, the mass balance can be written as

$$
\begin{aligned}
\frac{d M_{\mathrm{HA}, \text { liquid }}}{d t} & =m_{\mathrm{HA}, \text { in }, \mathrm{dig}}-m_{\mathrm{HA}, \mathrm{out}, \mathrm{dig}} \\
& +k_{a, \mathrm{HA}}\left(K_{a} C_{\mathrm{HA}}(t)-C_{\mathrm{H}^{+}}(t) C_{\mathrm{A}^{-}}(t)\right) V_{L} \\
& -\int m_{\mathrm{HA}, \text { gas }} d h .
\end{aligned}
$$

The last term is neglected if species does not have liquid/gas transfer and it is the integrated amount of the transferred species over the column height that needs to be considered in the liquid mass balance. 


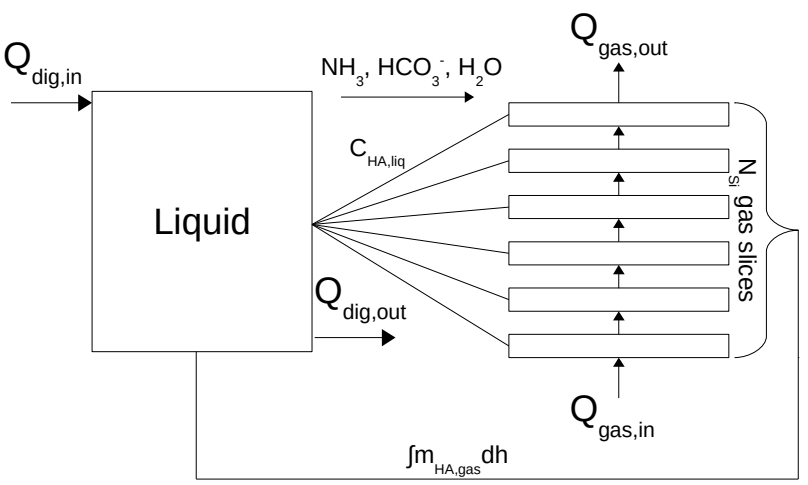

Figure 3. Proposed model structure

For HA gas species, the mass balance for any slice $S_{i}$ is

$$
\begin{aligned}
\frac{d M_{\mathrm{HA}, \mathrm{gas}}}{d t}= & m_{\mathrm{HA}, \mathrm{in}, \mathrm{gas}}\left|s_{i}-m_{\mathrm{HA}, \text { out, gas }}\right| s_{i} \\
& +\left(k_{L} a_{S}\left(C_{\mathrm{HA}, \mathrm{liq}}(t)-C_{\mathrm{HA}}^{*}(t, h)\right) V_{s i}\right) .
\end{aligned}
$$

For slice $S_{i}$, the volume tends to zero (sufficiently small slices), thus the previous equation becomes

$$
\begin{aligned}
\frac{d M_{\mathrm{HA}, \mathrm{gas}}}{d t}= & -d M_{\mathrm{HA}}(t, h) \\
& +\left(k_{L} a_{S}\left(C_{\mathrm{HA}, \mathrm{liq}}(t)-C_{\mathrm{HA}}^{*}(t, h)\right) A d h\right) .
\end{aligned}
$$

\subsubsection{Energy balances}

A simple approach is used for the energy balance calculation. The input air flow is considered to change quickly enough to the temperature of the column that it is instantaneous. The gas will also be instantaneously saturated by water (with respect to the new gas temperature) and thus, the mass of evaporated water can be calculated for the whole column.

Finally, the energy lost by the column when evaporating the water (in the output gas) can be calculated using the water vaporization enthalpy and the energy necessary to heat the air input from ambient temperature to the column temperature.

\section{Construction of Modelica model}

\subsection{Compilation of model equations}

Figure 3 shows how the liquid and gas are to be linked in the model. The $\mathrm{NH}_{3}$ species calculation progresses as follows. Given the liquid $\mathrm{p} H, \mathrm{p} K_{a}$ and TAN, $f_{\mathrm{NH}_{3}}, f_{\mathrm{NH}_{4}^{+}}$ and then $C_{\mathrm{NH}_{3}}, C_{\mathrm{NH}_{4}^{+}}$can be calculated from (8), (9) and (10).
The initial concentrations are calculated using

$$
\begin{aligned}
{\left[\mathrm{NH}_{3(\mathrm{aq})}\right]_{0} } & =f_{\mathrm{NH}_{3}} \mathrm{TAN}_{0} / M M_{\mathrm{TAN}} \\
{\left[\mathrm{NH}_{4}\right]_{0} } & =f_{\mathrm{NH}_{4}} \mathrm{TAN}_{0} / M M_{\mathrm{TAN}} \\
N_{\mathrm{org}} & =\mathrm{TKN}-\mathrm{TAN} \\
{\left[\mathrm{HCO}_{3}^{-}\right]_{0} } & =f_{\mathrm{HCO}_{3}^{-}} \mathrm{DIC}_{0} \\
{\left[\mathrm{CO}_{3}^{2-}\right]_{0} } & =f_{\mathrm{CO}_{3}^{2-}} \mathrm{DIC}_{0} \\
{\left[\mathrm{CO}_{2(\mathrm{aq})}\right]_{0} } & =f_{\mathrm{CO} 2(\mathrm{aq})} \mathrm{DIC}_{0}
\end{aligned}
$$

where mass fractions are found from equations (8), (10) and similar for DIC, and the molecular mass of TAN is $14 \mathrm{~g} / \mathrm{mol}$. TKN is Total Kjeldahl Nitrogen. DIC 0 is taken as $360 \mathrm{~mol} / \mathrm{m}^{3}$. The initial concentrations of hydrogen ion and hydroxide are

$$
\begin{aligned}
{\left[\mathrm{H}^{+}\right]_{0} } & =10^{-\mathrm{pH}} \\
{\left[\mathrm{OH}^{-}\right]_{0} } & =K_{a, \mathrm{OH}^{-} / \mathrm{H}^{+}} /\left[\mathrm{H}^{+}\right]_{0}
\end{aligned}
$$

This step is only needed to find the initial concentration of each species, and then the time dependent concentrations are found by resolution of the system of conservation equations. The concentration of $\mathrm{H}^{+}$is known during simulation meaning that $\mathrm{pH}$ is also known.

Equations (17) and (19) are solved for liquid and gas, respectively. The digestate inflow is assumed to be the same as the initial composition; $\mathrm{pH}_{0}, \mathrm{TAN}_{0}, \mathrm{DIC}_{0}, \mathrm{TKN}_{0}$. Then we can calculate

$$
m_{\mathrm{NH}_{3}, \text { in, dig }}=Q_{\mathrm{dig}, \mathrm{in}} C_{\mathrm{NH}_{3}, 0}
$$

while the digestate outflow has the same composition as the tank, hence

$$
m_{\mathrm{NH}, \mathrm{out}, \mathrm{dig}}=Q_{\mathrm{dig}, \mathrm{out}} C_{\mathrm{NH}_{3}}(t) .
$$

$Q_{\text {dig,out }}$ is the inflow minus the amount of evaporated water, which can be calculated independently of other equations as proposed at the end of this section

$$
Q_{\text {dig,out }}=Q_{\text {dig,in }}-m_{\mathrm{H}_{2} \mathrm{O}} / \rho \mathrm{H}_{2} \mathrm{O}_{(\mathrm{aq})} \text {. }
$$

In equation (17), mass transfers resulting from the change in concentration caused by changes in equilibrium are in the term

$$
k_{a}\left(K_{a} C_{\mathrm{NH}_{4}^{+}}(t)-\left(C_{\mathrm{H}^{+}}(t) C_{\mathrm{NH}_{3}}\right) V_{L}\right) .
$$

We need to make the gas calculation to find $\int m_{\mathrm{HA}, \mathrm{gas}} d h$ using equation (19) for each slice (note that it is easier to use equation (18) as the slices have a finite thickness, i.e. not tending towards zero). For each slice

$$
\begin{aligned}
\frac{d M_{\mathrm{NH}_{3}, \text { gas }}}{d t} & =\left.m_{\mathrm{NH}_{3}, \text { in, gas }}\right|_{S_{i}} \\
& -\left.m_{\mathrm{NH}_{3}, \text { out,gas }}\right|_{S_{i}}+\left.m_{\mathrm{NH}_{3}, \mathrm{gg}}\right|_{S_{i}}
\end{aligned}
$$




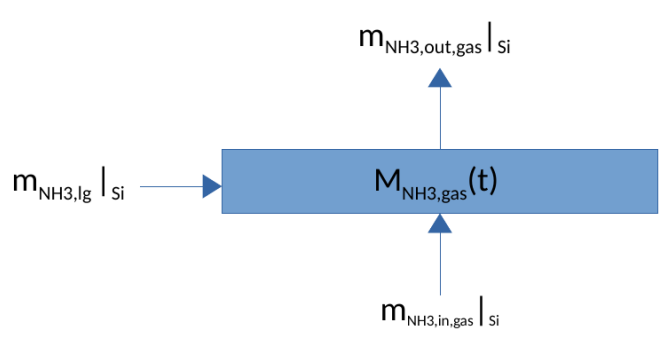

Figure 4. Mass transfers in and out of each gas slice.

where the liquid to gas transfer is $\left.m_{\mathrm{NH}_{3}, \lg }\right|_{S_{i}}=$ $k_{L} a_{\mathrm{NH}_{3}}\left(C_{\mathrm{NH}_{3} \text {, liq }}(t)-\left.C_{\mathrm{NH}_{3}}^{*}(t)\right|_{S_{i}}\right) V_{S_{i}}$ and the mass transfers in and out of each gas slice are summarized in Figure 4. The bottom slice has

$$
m_{\mathrm{NH}_{3}, \text { in, gas }}=Q_{\text {air }} C_{\mathrm{NH}_{3}} \text {, gas, } N_{0}=0,
$$

and for subsequent slices, the inter-slice mass flow rate for the $\mathrm{NH}_{3}$ species is

$$
m_{\mathrm{NH}_{3}} \text {, in, gas }\left.\right|_{i}=m_{\mathrm{NH}_{3}, \text { out, gas }} \mid S_{i}-1 .
$$

The liquid concentration $C_{\mathrm{NH}_{3}}$, liq is known from earlier calculations and the saturation concentration is calculated from

$$
C_{\mathrm{NH}_{3}}^{*}=C_{\mathrm{NH}_{3}, \text { gas }} \mid S_{i} / H_{\mathrm{NH}_{3}}^{c c},
$$

where $H_{\mathrm{NH}_{3}}^{c c}=\rho_{\mathrm{H}_{2} \mathrm{O}} H_{\mathrm{NH}_{3}}^{b p} R T_{L}$ and $\rho_{\mathrm{H}_{2} \mathrm{O}}=103 \mathrm{~kg} / \mathrm{m}^{3}, R=$ $8.206 \times 10^{-5} \mathrm{~m}^{3}$ atm / $(\mathrm{K} \mathrm{mol})$ and $1 / H_{\mathrm{NH}_{3}}^{b p}=0.016$ $\mathrm{atm} /(\mathrm{mol} / \mathrm{kg})$. The liquid temperature $T_{L}$ is chosen by the user, where $45^{\circ} \mathrm{C}$ is used in the demonstration shown later.

In order to calculate $\left.m_{\mathrm{NH}_{3} \text {,out,gas }}\right|_{S_{i}}$ in equation (32), the gas passing out of the slice is taken to have the same concentration as found in the slice, which is possible because the slices are sufficiently small. Hence $C_{\mathrm{g}, S_{i}}=$ $M_{\mathrm{NH}_{3}, \text { gas }} /\left(\rho_{\text {air }} V_{S_{i}}\right)$ and we can then say

$$
\left.m_{\mathrm{NH} 3, \text { out,gas }}\right|_{S_{i}}=C_{\mathrm{g}, S_{i}} \rho_{\mathrm{air}} Q_{\mathrm{air}} .
$$

The system is solved simultaneously for $t$ and $h$, and for each $d M / d t$ (or $V d C / d t$ ), where the only unknown variable in each equation is the concentration of the component itself or another component that also has its own $d M / d t$. Thus the number of equations and unknowns are the same, meaning that Modelica can now be used to find $M_{\mathrm{NH} 3 \text {,gas }}(t)$ for each slice, for a given initial $M_{\mathrm{NH} 3 \text {, gas }}(0)$.

The total mass transfer of $\mathrm{NH}_{3}$ from liquid to gas is calculated by summing across the slices

$$
\int m_{\mathrm{HA}, \mathrm{gas}} d h=\sum_{S_{i}} m_{\mathrm{NH}_{3}, \lg } \mid S_{i},
$$

which can then be used in (17). Equation (17) will apply to $\mathrm{NH}_{3}, \mathrm{CO}_{3}^{2-}, \mathrm{HCO}_{3}^{-} \mathrm{H}_{2} \mathrm{O}, \mathrm{H}^{+}, \mathrm{NH}_{4}^{+}, \mathrm{N}_{\text {org }}$, and so on. The calculation given above applies to reactions including $\mathrm{HCO}_{3}^{-}$, while all other $\mathrm{HA}$ species are the same apart from not having the liquid to gas mass transfer term at the end of (17).
The liquid species equations are too large to be reproduced here, but they have the form

$$
\begin{aligned}
& \frac{d M_{\mathrm{HA}}}{d t}=m_{\mathrm{HA}, \text { in }}-m_{\mathrm{HA}, \text { out }} \\
& \quad+k_{a, \mathrm{HB} / \mathrm{HA}}\left(K_{a, \mathrm{HB} / \mathrm{HA}}[\mathrm{HB}]-\left[\mathrm{H}^{+}\right][\mathrm{HA}]\right) V_{\mathrm{L}} \\
& \quad-\int m_{\mathrm{HA}, \mathrm{gas}} d h,
\end{aligned}
$$

with the last term only included if there is liquid to gas mass transfer.

In the case of $\mathrm{N}_{\text {org }}$ the reaction only goes in one direction (to $\mathrm{NH}_{4}^{+}$) and is controlled by $\mathrm{k}_{\text {ammonification (it should }}$ be easy to add saturation/inhibition coefficients later on). $\mathrm{k}_{\mathrm{ammonification}}$ has to be calibrated later when experimental data is available, but it can be set, for the moment, as a low value.

It is assumed that $C_{\mathrm{H}_{2} \mathrm{O}} \rightarrow 1$ because water is the solvent, and so it will not appear in the reaction equations (except for water evaporation). Values for $\mathrm{p} K_{a}$, and $K_{a}$ are given by the formulas as a function of temperature.

The equations used for the gas phases of $\mathrm{CO}_{2}$ and $\mathrm{NH}_{3}$ are then calculated. The calculations of $C^{*}$ for the gas phase species in a slice are made using

$$
\begin{gathered}
C_{\mathrm{NH}_{3} \mathrm{~g}}^{*}=C_{\mathrm{NH}_{3} \mathrm{~g}} /\left(\rho_{\mathrm{H}_{2} \mathrm{O}} R H_{\mathrm{NH} 3 \mathrm{~g}}^{b p} T_{L}\right), \\
C_{\mathrm{CO}_{2} \mathrm{~g}}^{*}=C_{\mathrm{CO}_{2} \mathrm{~g}} /\left(\rho_{\mathrm{H}_{2} \mathrm{O}} R H_{\mathrm{CO} 2 \mathrm{~g}}^{b p} T_{L}\right) .
\end{gathered}
$$

with the mass transfer rate to each slice from the liquid

$$
\begin{aligned}
& \left(m_{\mathrm{lg}, \mathrm{NH} 3 \mathrm{~g}}\right)_{\mathrm{sl}}=k_{L} a_{\mathrm{NH}_{3}} V_{\mathrm{L}, \mathrm{sl}}\left(C_{\mathrm{NH}_{3} \mathrm{l}}-C_{\mathrm{NH}_{3} \mathrm{~g}}^{*}\right), \\
& \left(m_{\mathrm{lg}, \mathrm{CO} 2 \mathrm{~g}}\right)_{\mathrm{sl}}=k_{L} a_{\mathrm{CO}_{2}} V_{\mathrm{L}, \mathrm{sl}}\left(C_{\mathrm{HCO}_{3}}-C_{\mathrm{CO}_{2} \mathrm{~g}}^{*}\right),
\end{aligned}
$$

and note the use of $\mathrm{CHCO}_{3}$ in (42).

We must calculate concentrations in the gas and for that it is necessary to have a gas volume per slice as we are working with the amount of substance (moles), hence

$$
\begin{aligned}
C_{\mathrm{NH}_{3} \mathrm{~g}} & =\frac{M_{\mathrm{NH}_{3} \mathrm{~g}}}{\rho_{\mathrm{air}} V_{\mathrm{L}, \mathrm{sl}} \alpha_{\mathrm{gas}}}, \\
C_{\mathrm{CO}_{2} \mathrm{~g}} & =\frac{M_{\mathrm{CO}_{2} \mathrm{~g}}}{\rho_{\mathrm{air}} V_{\mathrm{L}, \mathrm{sl}} \alpha_{\mathrm{gas}}} .
\end{aligned}
$$

Note, $\alpha_{\text {gas }}$ is the gas volume fraction of liquid, which is needed if we would like to know the concentration relative to gas volume (moles of $\mathrm{NH}_{3 g} / \mathrm{m}^{3}$ of gas).

The out-flowing molecular masses from a slice for each species are

$$
\begin{aligned}
& \left(m_{\mathrm{NH}_{3} \mathrm{~g}, \text { out }}\right)_{s l}=\left(C_{\mathrm{NH}_{3} \mathrm{~g}}\right)_{\mathrm{sl}} m_{\mathrm{air}}, \\
& \left(m_{\mathrm{CO}_{2} \mathrm{~g}, \text { out }}\right)_{s l}=\left(C_{\mathrm{CO}_{2} \mathrm{~g}}\right)_{\mathrm{sl}} m_{\mathrm{air}},
\end{aligned}
$$

where the slices are connected by making

$$
\begin{aligned}
\left(m_{\mathrm{NH}_{3} g, \text { in }}\right)_{s l} & =\left(m_{\mathrm{NH}_{3} \mathrm{~g}, \text { out }}\right)_{\mathrm{sl}}-1, \\
\left(m_{\mathrm{CO}_{2} g, \text { in }}\right)_{s l} & =\left(m_{\mathrm{CO}_{2} \mathrm{~g}, \text { out }}\right)_{\mathrm{sl}}-1 .
\end{aligned}
$$


Hence, the rate of change in moles of substance for each gas species in a slice is

$$
\begin{aligned}
& \frac{d M_{\mathrm{NH}_{3} \mathrm{~g}}}{d t}=m_{\mathrm{lg}, \mathrm{NH}_{3} \mathrm{~g}}+m_{\mathrm{NH}_{3} \mathrm{~g}, \text { in }}-m_{\mathrm{NH}_{3} \mathrm{~g}, \text { out }}, \\
& \frac{d M_{\mathrm{CO}_{2} \mathrm{~g}}}{d t}=m_{\mathrm{lg}, \mathrm{CO}_{2} \mathrm{~g}}+m_{\mathrm{CO}_{2} \mathrm{~g}, \text { in }}-m_{\mathrm{CO}_{2} \mathrm{~g}, \text { out }},
\end{aligned}
$$

assuming that the $\mathrm{H}_{2} \mathrm{O}$ immediately saturates the gas at the gas inflow temperature (ambient temperature). The gas will first be heated to achieve the column temperature and then an amount of water will be evaporated.

The rate of water mass evaporation can be calculated with

$$
m_{\mathrm{H}_{2} \mathrm{O}}=Q_{\text {air } 25^{\circ} \mathrm{C}} \rho_{\text {air } 25^{\circ} \mathrm{C}}\left(X_{T}-X_{25^{\circ} \mathrm{C}}\right)
$$

where $m_{\mathrm{H}_{2} \mathrm{O}}$ is the rate of evaporation in $\mathrm{kg}$ water $/ \mathrm{h}$, $Q_{\text {air } 25^{\circ} \mathrm{C}}$ is the volumetric flowrate of air at $25^{\circ} \mathrm{C}$ in $\mathrm{m}^{3} / \mathrm{h}$, $\rho_{\text {air } 25^{\circ} \mathrm{C}}$ is the density of air at $25^{\circ} \mathrm{C}$ in $\mathrm{kg} / \mathrm{m}^{3}, X_{T}$ is the absolute humidity of water at the working liquid temperature $T_{L}$ in kg water/kg "dry" air, $X_{25^{\circ} \mathrm{C}}$ is the absolute humidity of water at the inlet air temperature in $\mathrm{kg}$ water $/ \mathrm{kg}$ "dry" air.

The saturation pressure (in Pa) depends only on the air temperature (in ${ }^{\circ} \mathrm{C}$ ) and is calculated using the Magnus formula

$$
p_{\mathrm{H}_{2} \mathrm{O}}^{*}=611.23 \exp \left(\frac{17.5043 T}{T+242.2}\right),
$$

where $*$ denotes saturation. Partial pressure is calculated using $p_{\mathrm{H}_{2} \mathrm{O}}=R H p_{\mathrm{H}_{2} \mathrm{O}}^{*}$, where $R H$ is the relative humidity. The effect of humidity is seen in equations (53) and (51); in the case of $X_{T}$ we have $100 \% R H$ because the air is instantaneously saturated, and for $X_{25^{\circ} \mathrm{C}}$ we have $60 \% \mathrm{RH}$.

The absolute humidity in "dry" air $X$ (kg water/kg "dry" air) is found with

$$
X=\frac{p_{\mathrm{H}_{2} \mathrm{O}}}{P_{\mathrm{tot}}-p_{\mathrm{H}_{2} \mathrm{O}}} \frac{18}{28.84},
$$

and the air density depends only on temperature (in ${ }^{\circ} \mathrm{C}$ ) and can be calculated with

$$
\rho_{\text {air }}=1.292 \frac{273.25}{273.15+T} \frac{p_{\mathrm{H}_{2} \mathrm{O}}}{P_{\mathrm{tot}}},
$$

The rate of energy consumed by the system for water evaporation, in $\mathrm{kJ} / \mathrm{h}$, is then calculated by

$$
F_{\text {evap }}=m_{\mathrm{H}_{2} \mathrm{O}} \Delta H_{\text {vap water }} \text {, }
$$

where $\Delta H_{\text {vap water }}$ is the enthalpy of vaporization of water calculated using the correlation

$$
\Delta H_{\text {vap water }}=\frac{-0.0439 T_{L}+45.084}{0.018} .
$$

Note, this equation has $T_{L}$ in ${ }^{\circ} \mathrm{C}$ and $\Delta H$ with units $\mathrm{J} / \mathrm{kg}$. The air temperature is raised to the liquid temperature, meaning that

$$
F_{\text {air }}=Q_{\text {air }} C_{p, \text { air }} \rho_{\text {air }}\left(T_{L}-T_{G}\right) .
$$

The temperature of the bubble stripper is maintained by a heater and $F_{\text {evap }}+F_{\text {air }}$ is the power consumed.

\subsection{Modelica implementation}

The stripper model contains the definition of several smaller submodels (Figure 5). Liquid, gas and evaporated water have their own models. The gas phase is spatially 1D-discretised, as shown for the model in Section 2. This discretisation is achieved through the use of a 1D array of Slice models, with each slice being an elementary volume cell. Figure 5 shows the different connectors used to link the submodels.

The model is meant to be one component in a larger set or library, so the limit conditions are not defined in the stripper component, but are instead defined in external components (Figure 6).

Species are declared using the enumeration class type, e.g. species in the liquid phase

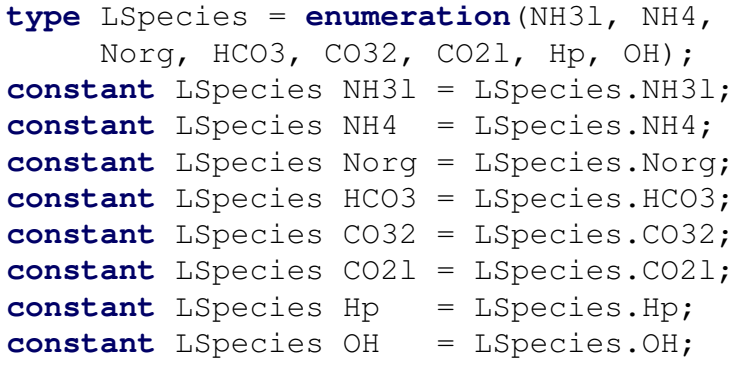

Then balance equations, such as

$$
\begin{aligned}
\frac{d M_{\mathrm{NH}_{3}, \text { liquid }}}{d t} & =m_{\mathrm{NH}_{3}, \text { in }, \text { dig }}-m_{\mathrm{NH}_{3}, \text { out }, \text { dig }} \\
& +k_{a, \mathrm{NH}_{4}}\left(K_{a} C_{\mathrm{NH}_{4}}(t)-C_{\mathrm{H}^{+}}(t) C_{\mathrm{NH}_{3}}(t)\right) V_{L} \\
& -\int m_{\mathrm{NH}_{3}, \text { gas }} d h,
\end{aligned}
$$

(see Eq. (17)), are easily written in Modelica code as

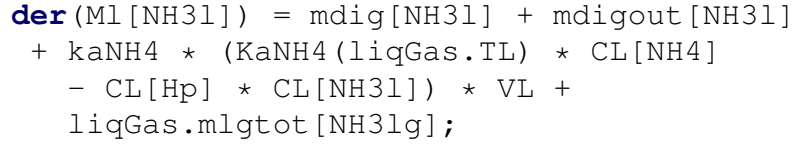

given that we have previously defined ${ }^{2}$

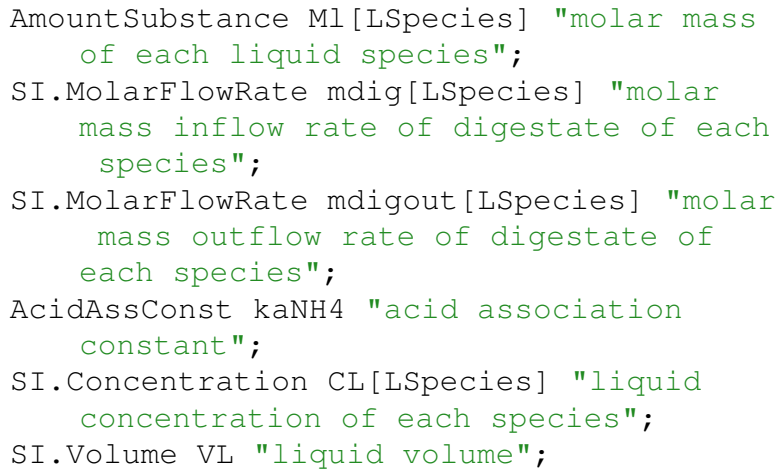

with function KaNH4 and a connector LiqGas of type LiquidGas (Figure 5). Note that there are differences

\footnotetext{
${ }^{2}$ Units prefixed with SI are from package Modelica.SIunits. The other ones are custom units.
} 


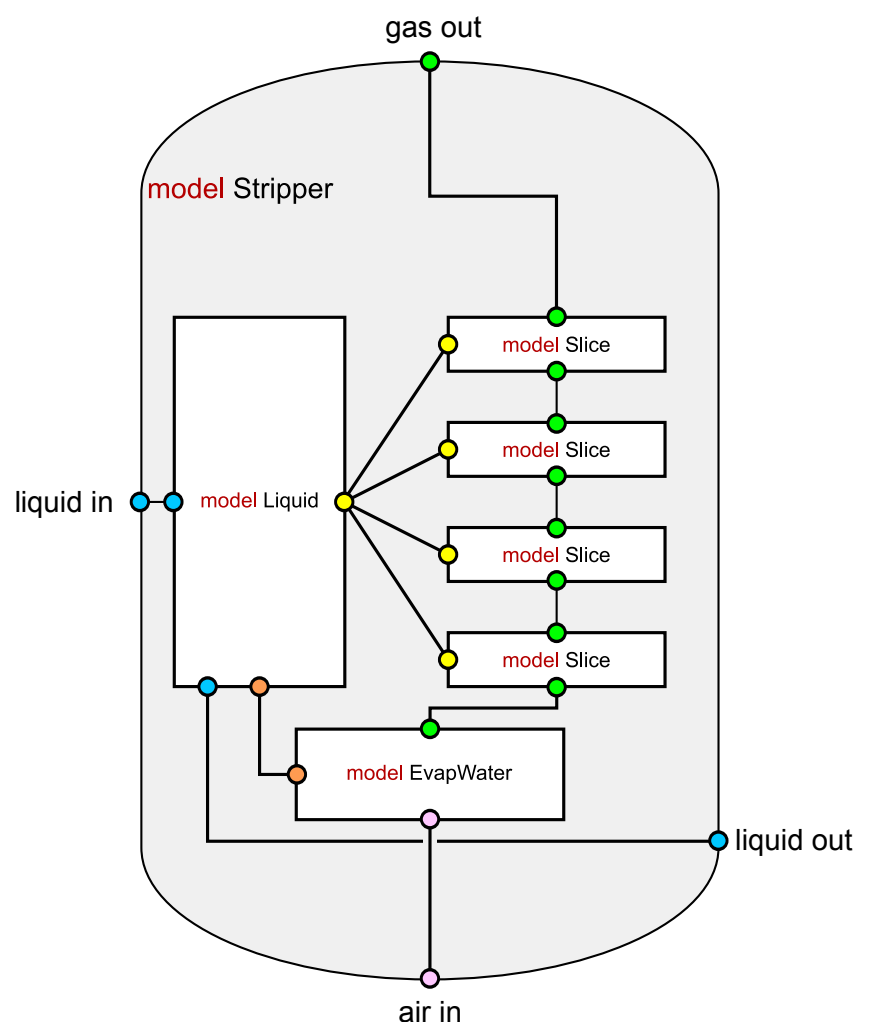

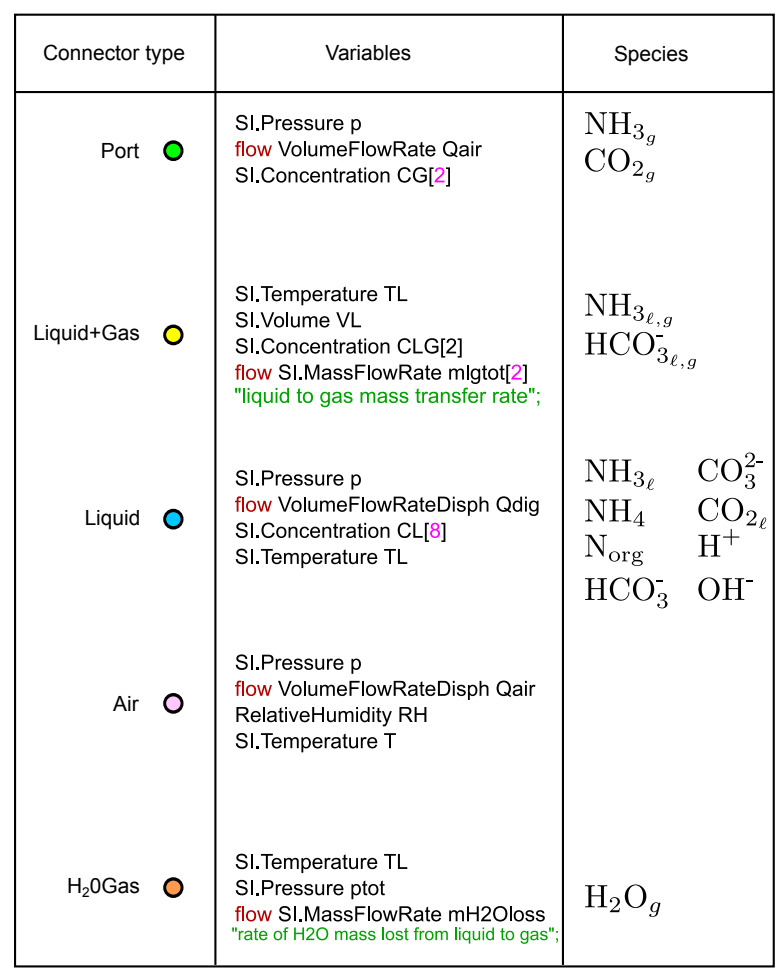

Figure 5. Stripper hierarchical model as implemented in Modelica. The stack of slices defines the spatial discretisation of the gas phase. The number of slices can be varied, with four being represented in the this figure. The connections between the slices are created automatically inside a for loop. The table lists the different connectors used in the stripper model, with their variables. Some of the variables are arrays (e.g. concentration in Port). Each element of an array is related to a chemical species in the right-hand column of the table.

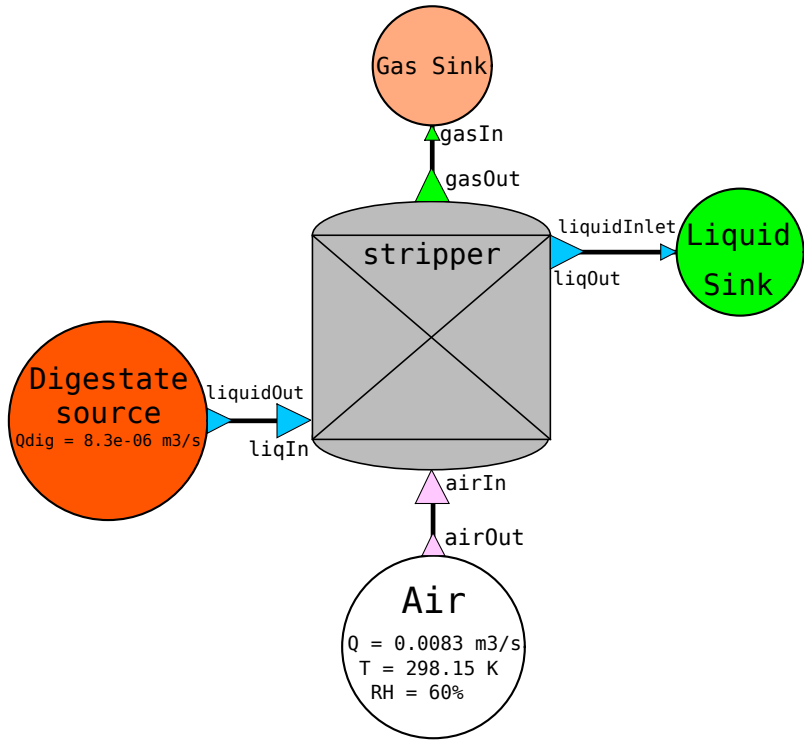

Figure 6. Modelica stripper model connected to other models to specify limit conditions. in the signs before the flow rate variables. In Modelica models, the flow variables are signed ${ }^{3}$ so that the outflow variables are added in the Modelica equations.

\section{Results}

The trend for the change in $\mathrm{pH}$ found by the simulation (Figure 7) is similar to that observed in experiment, but time scales differ. It will be necessary to make careful studies to find good values for all parameters before reliable predictions can be made.

\section{Conclusion}

A simple model for an ammonia stripper has been created using Modelica, which is a further demonstration of the use of Modelica in process engineering applications for problems including chemical reactions. The correct trend has been shown by results with increasing $\mathrm{pH}$ with time. There is now a need for experimental data to further validate and calibrate the model. Depending on the comparison with experiment, improvement can be made by considering the high ionic strength of the digestate, where the concentration needs to be corrected using activity coefficients. Compressor and pump calculations could also be

\footnotetext{
${ }^{3}$ Positive if the corresponding entity enters the component, negative if it leaves.
} 


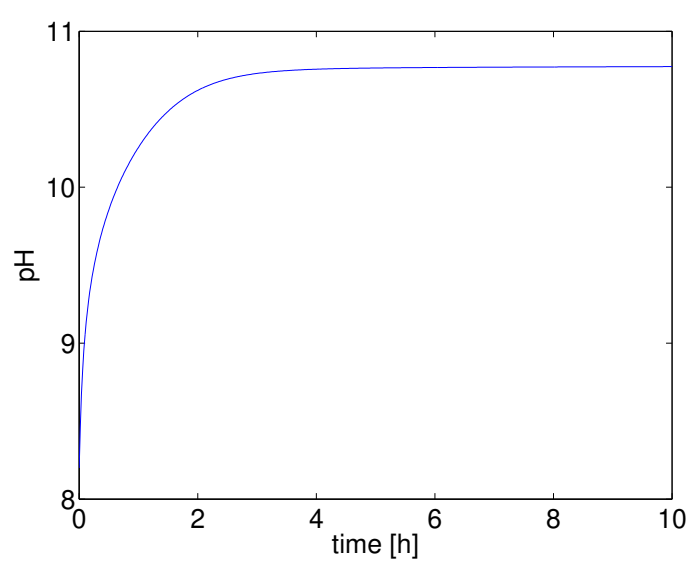

Figure 7. Change in $\mathrm{p} H$ with time.

made.

\section{References}

Johan Åkesson, R Faber, CD Laird, K Prölss, H Tummescheit, $\mathrm{S}$ Velut, and Y Zhu. Models of a post-combustion absorption unit for simulation; optimization and non-linear model predictive control schemes. In Proceedings of the 8th International Modelica Conference; March 20th-22nd; Technical Univeristy; Dresden; Germany, number 063, pages 64-74. Linköping University Electronic Press, 2011.

Ali Baharev and Arnold Neumaier. Chemical process modeling in modelica. In Proceedings of the 9th International MODELICA Conference; September 3-5; 2012; Munich; Germany, number 76, pages 955-962. Linköping University Electronic Press, 2012.

François E Cellier and Jürgen Greifeneder. Modeling chemical reactions in modelica by use of chemo-bonds. In Proceedings of the 7th International Modelica Conference; Como; Italy; 20-22 September 2009, number 043, pages 142-150. Linköping University Electronic Press, 2009.

J Fernandez De Canete, Alfonso Garcia-Cerezo, Inmaculada García-Moral, P Del Saz, and Ernesto Ochoa. Objectoriented approach applied to anfis modeling and control of a distillation column. Expert Systems with Applications, 40 (14):5648-5660, 2013.

Rahul Jain, Kannan M Moudgalya, Peter Fritzson, and Adrian Pop. Development of a thermodynamic engine in openmodelica. In Proceedings of the 12th International Modelica Conference, Prague, Czech Republic, May 15-17, 2017, number 132, pages 89-99. Linköping University Electronic Press, 2017.

Andreas Joos, Karin Dietl, and Gerhard Schmitz. Thermal separation: An approach for a modelica library for absorption; adsorption and rectification. In Proceedings of the 7th International Modelica Conference; Como; Italy; 20-22 September 2009, number 043, pages 804-813. Linköping University Electronic Press, 2009.

Uwe Küssel, Dirk Abel, Matthias Schumacher, and Martin Weng. Modeling of rotary kilns and application to limestone calcination. In Proceedings of the 7th International Modelica Conference; Como; Italy; 20-22 September 2009, number 043, pages 814-822. Linköping University Electronic Press, 2009.

I Lizarralde, T Fernández-Arévalo, C Brouckaert, P Vanrolleghem, DS Ikumi, GA Ekama, E Ayesa, and P Grau. A new general methodology for incorporating physico-chemical transformations into multi-phase wastewater treatment process models. Water research, 74:239-256, 2015.

Thomas Marx-Schubach and Gerhard Schmitz. Optimizing the start-up process of post-combustion capture plants by varying the solvent flow rate. In Proceedings of the 12th International Modelica Conference, Prague, Czech Republic, May 15-17, 2017, number 132, pages 121-130. Linköping University Electronic Press, 2017.

Christine Matter-Müller, Willi Gujer, Walter Giger, and Werner Stumm. Non-biological elimination mechanisms in a biological sewage treatment plant. In Water Pollution Research and Development, pages 299-314. Elsevier, 1981.

Hubertus Tummescheit and Jonas Eborn. Chemical reaction modeling with thermofluid/mf and multiflash. In Proceedings of the 2th Modelica Conference, 2002.

C. Vaneeckhaute, F.H.A. Claeys, F.M.G. Tack, E. Meers, E. Belia, and P.A. Vanrolleghem. Development, implementation, and validation of a generic nutrient recovery model (nrm) library. Environmental Modelling \& Software, 99:170 - 209, 2018.

Johan Windahl, Katrin Prölss, Maarten Bosmans, Hubertus Tummescheit, Eli van Es, and Awin Sewgobind. Multicomponentmultiphase-a framework for thermodynamic properties in modelica. In Proceedings of the 11th International Modelica Conference, Versailles, France, September 21-23, 2015, number 118, pages 653-662. Linköping University Electronic Press, 2015. 